\title{
Utilização do amido da amêndoa da manga Tommy Atkins como espessante em bebida láctea
}

\author{
Geraildo A. S. Silva', Mônica T. Cavalcanti' ${ }^{2}$, Maria C. B. de M. Almeida', \\ Alfredina dos S. Araújo ${ }^{2}$, Gerla C. B. Chinelate ${ }^{3} \&$ Eliane R. Florentino ${ }^{4}$
}

\begin{abstract}
RESUMO
O processamento industrial da manga gera um grande volume de resíduos que não são reaproveitados mas descartados de forma inadequada. O objetivo deste trabalho foi extrair o amido da amêndoa da manga Tommy Atkins e utilizá-lo como espessante em bebida láctea. Para ser utilizado em bebida láctea em três concentrações $(1,2 ; 0,6$ e $0,3 \%$ o amido foi caracterizado através de análises físico-químicas e microbiológicas e, por microscopia eletrônica de varredura, a morfologia dos grânulos, capacidade de gelificação $(1,2 ; 0,6$ e $0,3 \%)$ e só então submetido à análise sensorial. O amido apresentou rendimento de extração de $59,82 \%$ em peso de amêndoas com umidade de $10,14 \%$, proteína de $2,33 \%$, cinzas de $0,35 \%$ e lipídios de $4,67 \%$, além da isenção de micro-organismos patogênicos. O formato do grânulo de amido foi irregular, entre esféricos a elipsoidais, com tamanhos diferenciados. A concentração mínima de gelificação foi observada em $6 \%$ de amido. A bebida láctea elaborada mostrou-se viável à comercialização por apresentar boas características sensoriais e físico-químicas utilizando-se $0,3 \%$ de amido como espessante. O amido apresentou características desejáveis podendo ser largamente utilizado.
\end{abstract}

Palavras-chave: Mangifera indica L., aproveitamento de resíduos, produtos lácteos

\section{Use of starch of almond of Tommy Atkins mango as thickener for dairy beverages}

\begin{abstract}
The industrial processing of mango generates a large volume of waste, which is not reused or properly disposed. This study aimed to extract starch from almond of Tommy Atkins mango and use it as a thickener in dairy beverages. The starch was characterized by physicochemical and microbiological analysis, and the granule morphology and gelling ability were observed by scanning electron microscopy, and used in dairy beverages at three concentrations $(1.2,0.6$ and $0.3 \%)$, being submitted to sensory analysis. The starch showed extraction yield of $59.82 \%$ by weight of almonds with $10.14 \%$ moisture, $2.33 \%$ protein, $0.35 \%$ ash, $4.67 \%$ fat, and absence of pathogenic microorganisms. The shape of starch granules was irregular between spherical to ellipsoidal with different sizes. The minimum gelling concentration was observed in $6 \%$ starch. The prepared dairy beverages showed viable commercialization by presenting good sensory and physico-chemical characteristics, using $0.3 \%$ starch as thickener. The starch showed desirable characteristics, which can be widely used.
\end{abstract}

Key words: Mangifera indica L., waste, utilization, dairy products

\footnotetext{
' Programa de Pós-Graduação em Sistemas Agroindustriais/UFCG, Rua Jairo Vieira Feitosa, s/n, Bairro dos Pereiros, CEP 58840-000, Pombal, PB. Fone: (83) 3431-4000. E-mail: alexandregeraildo@gmail.com; climenemedeiros@yahoo.com.br

2 UATAVUFCG, Rua Jairo Vieira Feitosa, s/n, Bairro dos Pereiros, CEP 58840-000, Pombal, PB. Fone: (83) 3431-4000. E-mail: monicatejoc@yahoo.com.br; alfredina@ccta.ufcg.edu.br

${ }^{3}$ UAG/UFRPE, Avenida Bom Pastor, Boa Vista, CEP 55292-270, Garanhuns, PE. Fone: (87) 3764-5500. E-mail: gerla.chinelate@yahoo.com.br

${ }^{4}$ CCT/UEPB. Avenida das Baraúnas, s/n, Bodocongó, CEP 58429-500, Campina Grande, PB. Fone: (83) 8881-9340. E-mail: elianerf@yahoo.com.br
} 


\section{INTRODUÇÃO}

A manga é uma das frutas tropicais mais consumidas em todo o mundo. Há algumas centenas de variedades conhecidas, mas de pequena importância comercial devido a características pouco desejáveis, como tamanho pequeno e grande quantidade de fibras e fiapos. Cultivares comerciais, como a cultivar Tommy Atkins, resultam de extensas pesquisas de seleção e melhoramento genético o que levou essa variedade a ser a preferida dos agricultores brasileiros respondendo por cerca de $80 \%$ da área cultivada no Brasil (Almeida et al., 2001).

A polpa de manga tem grande importância como matériaprima em indústrias de frutas e outras que utilizam a polpa de fruta como parte da formulação de iogurtes, doces, biscoitos, bolos, sorvetes, refrescos e alimentos infantis (Benevides et al., 2008).

O setor agroindustrial produz grandes quantidades de resíduos e podem apresentar sérios problemas de disposição sendo potenciais poluentes. Aproximadamente 40 a $60 \%$ de resíduos são gerados durante o processamento de mangas, 12 a $15 \%$ se constituem de cascas e 15 a $20 \%$, de caroços (endocarpos) (Kaur et al., 2004). O aproveitamento integral de alimentos é uma alternativa para suprir as necessidades nutricionais, agregar valores ao agronegócio e reduzir o lixo orgânico (Oliveira et al., 2002).

Diversos pesquisadores já estudaram o resíduo da manga, como Velan et al. (1995) através da conversão do amido do caroço da manga em xaropes de glicose, por hidrólise enzimática, Chowdary et al. (2000) estudaram a otimização por meio da metodologia de superfície de resposta da hidrólise enzimática do amido do caroço da manga e Kaur et al. (2004) estudaram as propriedades físico-químicas, morfológicas, térmicas e reológicas do amido dos caroços de cinco cultivares indianas de manga e as compararam com outras fontes comerciais de amido concluindo que são comparáveis com o amido de milho, trigo, arroz e batata e poderia ser eficazmente utilizada como fonte de amido.

Amidos nativos têm sido usados desde tempos antigos para preparar diferentes produtos. Amido é o produto amiláceo extraído das partes aéreas comestíveis dos vegetais e fécula é o produto amiláceo extraído das partes subterrâneas comestíveis dos vegetais. O produto deverá ser designado amido ou fécula, seguido do nome do vegetal de origem, tais como amido de milho, fécula de batata (Adebowale et al., 2006; Kaur et al., 2006).

Nas indústrias agroalimentares os amidos e derivados são utilizados como ingredientes, componentes básicos ou aditivos adicionados em baixas quantidades para melhorar a fabricação, apresentação ou conservação do produto desempenhando, assim, papel relevante no controle das características de um grande número de alimentos processados (Serrano \& Franco, 2005).

No Brasil, a produção de bebidas lácteas é uma das principais opções de aproveitamento do soro de leite (Capitani et al., 2005). O soro de leite pode ser definido como líquido remanescente do processo de fabricação de queijos, retendo cerca de $55 \%$ dos nutrientes contidos naturalmente no leite (Sgarbieri, 2008; Lira et al., 2009).
A fim de aproveitar resíduos industriais na formulação de produtos alimentícios, este trabalho propôs obter e caracterizar o amido da amêndoa do endocarpo da manga, variedade Tommy Atkins, proveniente dos resíduos agroindustriais de polpa de fruta congelada do sertão da Paraíba e avaliar sua utilização como espessante em bebida láctea fermentada.

\section{Material e Métodos}

A matéria-prima utilizada no desenvolvimento deste trabalho foi a amêndoa contida no endocarpo da manga (Mangifera indica L.) variedade Tommy Atkins, provenientes de uma agroindústria de polpa de frutas localizada no Assentamento São João do município de Pombal, estado da Paraíba. O trabalho foi realizado no período compreendido entre dezembro de 2011 a agosto de 2012. Os endocarpos das mangas passaram pela fase de beneficiamento após o que foram separados de contaminantes e impurezas, lavados em água corrente e quebrados manualmente com auxílio de uma faca de inox, obtendo-se as amêndoas. Foi obtido aproximadamente $1,6 \mathrm{~kg}$ de amêndoas, processadas em 8 lotes de $200 \mathrm{~g}$ cujo rendimento de extração do amido da amêndoa da manga Tommy Atkins foi calculado em relação à matéria seca.

Obteve-se o amido pelo método descrito por Adebowale et al. (2006) com adaptações, em que as amêndoas foram submersas em solução de bissulfito de sódio a $1 \%$ com água refrigerada $\left(5^{\circ} \mathrm{C}\right)$, com $\mathrm{pH}$ entre 4,6 e 5,2 e deixadas em repouso durante $24 \mathrm{~h}$; após esta etapa as amêndoas foram trituradas em liquidificador industrial da marca Fak com capacidade para $8 \mathrm{~L}(600 \mathrm{~W})$, em velocidade máxima por aproximadamente 3 min com água destilada e tamisadas em peneira com malha de 80 mesh.

A suspensão de amido filtrado foi decantada pelo tempo de $24 \mathrm{~h}$, em ambiente refrigerado a $5^{\circ} \mathrm{C}$; em seguida à decantação a suspensão teve seu sobrenadante descartado e três lavagens do amido foram feitas com água destilada. $\mathrm{O}$ resíduo obtido foi transferido para bandejas de alumínio e secado em estufa de circulação e renovação de Ar SL 102 da Solab a $45^{\circ} \mathrm{C}$ por aproximadamente $3 \mathrm{~h}$. O amido foi estocado em sacos de polietileno e armazenado até seu uso.

A composição centesimal, umidade (método 012/IV), cinzas (método 018/IV), lipídios (método 032/IV) e proteínas (método 036/IV), da amêndoa e do amido obtido foram determinados conforme os procedimentos analíticos do Instituto Adolfo Lutz (Brasil, 2005a). As determinações do teor de cinzas, umidade, lipídeos e proteínas, foram realizadas em triplicata e o resultado médio expresso seguido do respectivo desvio padrão. O conteúdo de carboidratos totais, incluindo fibras, foi calculado por diferença de 100 da soma dos percentuais dos demais componentes da composição centesimal. A quantificação do amido foi realizada de acordo com o método de antrona cujo princípio se baseia na determinação espectrofotométrica a $620 \mathrm{~nm}$ do composto colorido formado pela reação entre a antrona e a glicose proveniente da hidrólise do amido (Labanca et al., 1999).

A avaliação da morfologia do grânulo de amido foi realizada por Microscópio Eletrônico de Varredura (MEV); trata-se de um equipamento capaz de produzir imagens de alta 
ampliação (até $300.000 \mathrm{X}$ ) e resolução. A caracterização do amido por MEV, foi realizada no equipamento fabricado pela HITACHI® (Tokyo, Japão), modelo TM 1000, acoplado a um sistema para microanálise química por Espectroscopia de Energia Dispersiva - EDS, visando conferir condutividade ao amido enquanto as amostras foram recobertas com ouro. Cinco imagens dos grânulos foram captadas, dentre as quais apenas duas se apresentaram mais nítidas.

As amostras de amido em triplicata foram submetidas às seguintes análises microbiológicas: contagem de Bacillus cereus, pesquisa de Salmonella, determinação do Número Mais Provável (NMP) de coliformes termotolerantes e bolores e leveduras. A metodologia adotada foi a recomendada pela Agência Nacional de Vigilância Sanitária (ANVISA), RDC n. 12 de 02 de janeiro de 2001, de acordo com a metodologia estabelecida pelo Ministério da Agricultura, Pecuária e Abastecimento - MAPA (Brasil, 2001).

O método utilizado por Lawal \& Adebowale (2005) foi aplicado para o estudo de geleificação do amido. As amostras de amido nas concentrações de 2, 4, 6, 8, 10, 12, 14\% (p/v), foram preparadas em tubos de ensaio com $5 \mathrm{~mL}$ de água destilada, em triplicata, mixadas por 5 min e os tubos foram aquecidos em banho-maria com termostato, durante $30 \mathrm{~min}$ a $80{ }^{\circ} \mathrm{C}$, seguidos de resfriamento em água corrente fria; posteriormente, os tubos foram resfriados a $4{ }^{\circ} \mathrm{C}$, por $2 \mathrm{~h}$; enfim, a concentração mínima de geleificação foi determinada como aquela concentração em que a amostra do tubo invertido não escorrega pelo tubo.

As bebidas lácteas fermentadas foram elaboradas dentro dos padrões da legislação específica (Brasil, 2005b) utilizando-se o amido da amêndoa do endocarpo da manga como espessante; de início, preparou-se o inóculo utilizando-se cultura láctea liofilizada (Marca SACCO srl, Lyofast, Y 456 B, lote $\mathrm{n}^{\circ}$ C041293A, validade 08/2013) contendo os micro-organismos Lactobacillus delbrueckii ssp. bulgaricus e Streptococcus thermophilus, utilizando-se leite UHT, pasteurizado a $90{ }^{\circ} \mathrm{C}$, por $15 \mathrm{~min}$, resfriado a $43^{\circ} \mathrm{C} ; 0,1 \mathrm{~g}$ da cultura láctea liofilizada starter foi inoculado, homogeneizado e incubado a $43{ }^{\circ} \mathrm{C}$, durante $6 \mathrm{~h}$. Foi elaborado $1 \mathrm{~L}$ de bebida láctea para cada formulação, em 3 lotes.

As bebidas lácteas fermentadas foram elaboradas segundo formulação apresentada na Tabela 1 , incubadas a $43^{\circ} \mathrm{C}$, durante $8 \mathrm{~h}$ de fermentação.

Tabela 1. Formulação das bebidas lácteas fermentadas utilizando-se o amido da amêndoa da manga como espessante

\begin{tabular}{lrcc}
\hline \multicolumn{1}{c}{$\begin{array}{c}\text { Ingredientes } \\
\text { (\%) }\end{array}$} & \multicolumn{3}{c}{ Formulação } \\
\cline { 2 - 4 } Leite UHT integral & $\mathbf{1}$ & $\mathbf{2}$ & $\mathbf{3}$ \\
Soro de leite & 51,0 & 51,0 & 51,0 \\
Sacarose & 32,8 & 33,4 & 33,7 \\
Amido da manga & 10,0 & 10,0 & 10,0 \\
Preparado de polpa de morango & 1,2 & 0,6 & 0,3 \\
Inóculo & 3,0 & 3,0 & 3,0 \\
\hline
\end{tabular}

Os ingredientes leite UHT integral, soro de leite, sacarose e amido da amêndoa da manga, foram misturados e submetidos a pasteurização a $95^{\circ} \mathrm{C}$, por $5 \mathrm{~min}$, resfriados a $42^{\circ} \mathrm{C}$ e então inoculado. A incubação foi realizada em estufa de fermentação a $42{ }^{\circ} \mathrm{C}$ por $8 \mathrm{~h}$; após o processo fermentativo o produto foi resfriado a $4{ }^{\circ} \mathrm{C}$, homogeneizado e ao mesmo incorporado o preparado de polpa de morango; a bebida láctea fermentada foi acondicionada em embalagens de polietileno de alta densidade e armazenadas sob refrigeração a $4{ }^{\circ} \mathrm{C}$ até análise.

Os provadores foram caracterizados conforme a ficha de identificação inicial da análise sensorial, considerando-se: gênero, grau de escolaridade, idade e frequência de consumo.

$\mathrm{O}$ produto elaborado nas três formulações foi avaliado sensorialmente utilizando-se metodologias 154/IV e 160/IV do Instituto Adolfo Lutz (Brasil, 2005a) comparando-o com uma amostra de bebida láctea fermentada sabor morango comercial, fabricada na cidade de Sousa, PB, Brasil, com prazo de validade de 45 dias. Foram utilizados, para a análise sensorial, $2 \mathrm{~L}$ de cada formulação elaborada, além da amostra comercial de um mesmo lote.

O teste foi conduzido com 60 provadores não-treinados, de ambos os gêneros, representando o público consumidor do produto, os quais receberam quatro amostras de aproximadamente $50 \mathrm{~mL}$, utilizando uma escala hedônica verbal de 9 pontos, com escores variando de 9 (gostei muitíssimo) até 1 (desgostei muitíssimo); os atributos sensoriais de aceitação global, textura e aparência, foram avaliados através de uma ficha de avaliação sensorial; foi avaliada, também, a intenção de compra, em que os provadores assinalaram, na escala de cinco pontos $(5=$ Certamente compraria a $1=$ Certamente não compraria). Considerou-se índice de aceitação como sendo a soma da frequência dos valores superiores a " 6 " e o índice de rejeição como a soma da frequência dos valores inferiores a "4" na escala hedônica de 9 pontos.

As amostras foram servidas em copos descartáveis, na temperatura de $10{ }^{\circ} \mathrm{C}$; devidamente codificadas foram apresentadas, aleatoriamente, aos provadores em cabines individuais, juntamente com um copo contendo água mineral a temperatura ambiente para o enxágue bucal entre as degustações cujo procedimento foi efetuado em cabines individuais em sala com luz branca, equivalente à luz do dia.

O Comitê de Ética da Universidade Estadual da Paraíba, localizado em Campina Grande, PB, aprovou, em 9 de dezembro de 2011 pelo processo CAAE: 0723.0.133.000-11, a realização da análise sensorial.

A bebida láctea mais aceita na avaliação sensorial foi analisada quanto ao teor de umidade utilizando-se balança determinadora de umidade por infravermelho (marca Marte, ID 200), extrato seco total, $\mathrm{pH}$ em potenciômetro digital e acidez em ácido lático com resultado expresso em Dornic $\left({ }^{\circ} \mathrm{D}\right)$ que corresponde a $1 \mathrm{~mL}$ de solução de $\mathrm{NaOH} 0,1 \mathrm{M}$ consumido na titulação, equivalendo a $0,0090 \mathrm{~g}$ de ácido lático (Brasil, 1981). $\mathrm{O}$ teor de gordura, de proteína e de cinzas, foram realizados seguindo metodologia recomendada pelo Instituto Adolfo Lutz (Brasil, 2005a).

$\mathrm{Na}$ análise sensorial o número de provadores equivale às repetições e nas demais análises se obtiveram os resultados médios de três repetições das análises, seus respectivos desvios padrões, que foram comparados através do teste de Tukey considerando-se o nível de probabilidade de erro (p) menor que 0,05 para determinar a significância utilizando-se o programa 
estatístico SPSS ${ }^{\circledR}$ (Statistical Package for the Social Sciences) for Windows - 11.0.

\section{Resultados E Discussão}

Os componentes centesimais das amêndoas contidas no endocarpo da manga, variedade Tommy Atkins e do amido extraído, estão apresentados na Tabela 2.

Tabela 2. Componentes centesimais da amêndoa da manga e amido extraído\#

\begin{tabular}{lcc}
\hline Componentes centesimais & Amêndoa da manga & Amido extraído \\
Umidade (\%) & $64,78 \pm 0,66$ & $10,14 \pm 0,69$ \\
Cinzas (\%) & $0,54 \pm 0,27$ & $0,35 \pm 0,12$ \\
Proteínas (\%) & $2,00 \pm 0,64$ & $2,33 \pm 0,21$ \\
Lipídeos (\%) & $6,52 \pm 0,04$ & $4,67 \pm 0,10$ \\
Carboidratos* (\%) & 26,16 & 82,51 \\
pH & $5,61 \pm 0,10$ & $6,75 \pm 0,02$ \\
\hline
\end{tabular}

\# Valores médios de três repetições seguido do respectivo desvio padrão.

* Carboidratos por diferença (100 menos a soma dos demais componentes)

A amêndoa da manga apresentou teor de umidade de $64,78 \%$ bem superior, portanto, ao da amêndoa da manga espada, com teor de 39,74\% (Cavalcanti et al., 2011) e da manga variedade ubá, com 11,64\% (Vieira et al., 2009). A amêndoa da manga apresentou teor de umidade elevado, provavelmente, pelo fato da matériaprima não ter passado por um processo prévio de secagem.

A amêndoa da manga Tommy Atkins apresentou conteúdo de carboidratos de $26,16 \%$. Com relação ao $\mathrm{pH}$, a amêndoa da manga apresentou pH de 5,61. Cavalcanti et al. (2011) estudaram o teor de carboidratos das amêndoas da manga espada e obtiveram valores de $47,16 \%$ dos quais $44,76 \%$ amido. Dependendo da variedade da manga, a amêndoa contida no endocarpo pode conter aproximadamente $6,0 \%$ de proteína, $11 \%$ de gordura, $77 \%$ de carboidratos, $2,0 \%$ de fibra bruta e $2,0 \%$ de cinzas, com base no peso seco médio (Zein et al., 2005).

$\mathrm{O}$ amido extraído da amêndoa do endocarpo da manga Tommy Atkins apresentou rendimento de 59,82\% em peso de amêndoas e teor de amido de $90,00 \%$. Cavalcanti et al. (2011) obtiveram rendimento de $72,50 \%$ em peso de amêndoas da manga espada.

Embora o amido seja constituído basicamente de carboidratos, outras substâncias como lipídeos, proteínas e cinzas, estão presentes em sua composição e a quantidade desses constituintes no amido depende da composição da planta e do método de extração e purificação utilizados (Daiuto et al., 2002).

$\mathrm{O}$ amido estudado obteve $82,51 \%$ de carboidratos, sendo este nutriente o que se apresentou em maior concentração seguido do teor de umidade, com 10,14\%, lipídios, com 4,67\%, proteínas, com $2,33 \%$ e cinzas com $0,35 \%$. Valores aproximados foram obtidos por Adebolwale et al. (2006) que, estudando o amido obtido de semente de sword (Canavalia gladiata) obtiveram umidade de $13,1 \%$, cinzas de $0,9 \%$, proteínas de $0,2 \%$, lipídios de $0,1 \%$, carboidratos de $85,6 \%$ e pH de 6,6 . Lawal \& Adebolwale (2005) obtiveram, estudando o amido da semente da jaca (Canavalia ensiformis) umidade de 12,35\%, cinzas de $0,33 \%$, proteínas de $1,02 \%$, lipídios de $0,1 \%$ e pH de 7,07. Leonel \& Cereda (2002) encontraram, estudando a fração amilácea da araruta (Maranta arundinacea), umidade de $12,79 \%$, cinzas de $0,18 \%$, proteínas de $0,10 \%$, lipídios de
$0,11 \%$ e pH de 6,37 e Leonel et al. (2003) caracterizaram o amido de jacatupé (Pachyrhizu sahipa) e obtiveram umidade de $12,31 \%$, cinzas de $0,28 \%$, proteínas de $0,10 \%$, lipídios de $0,41 \%$ e $\mathrm{pH}$ de 6,45 .

A forma e o tamanho dos grânulos de amido nativo são distintos entre as espécies vegetais, os grânulos são organizados em zonas cristalinas alternadas por outras semi-cristalinas devido à alternância dos períodos de síntese ocorridos nos amiloplastos. As Figuras 1A e 1B apresentam imagens para microscopia eletrônica de varredura para o amido extraído das amêndoas da manga com aumento de "1000 e 5000x", respectivamente.

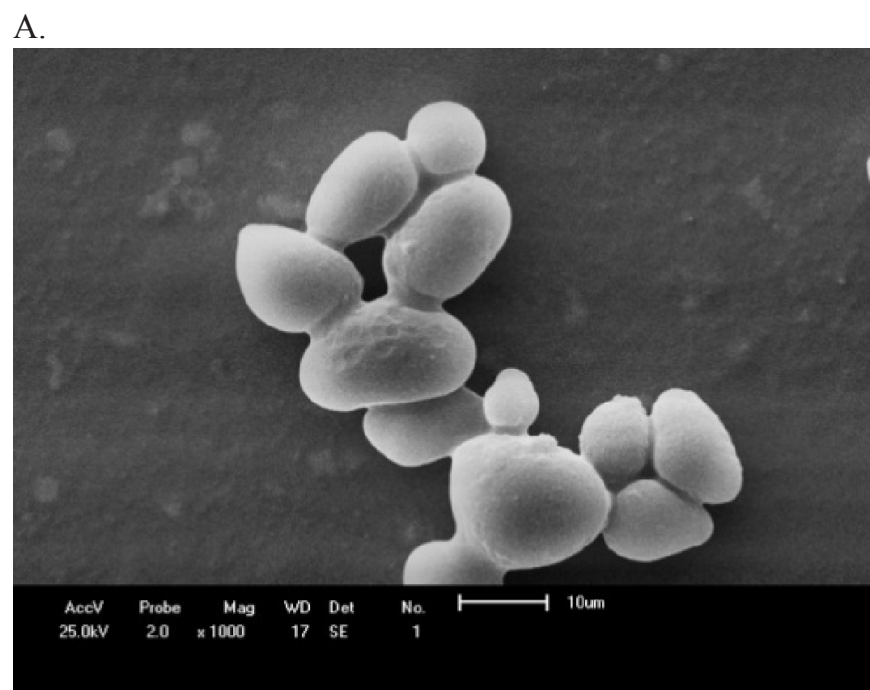

B.

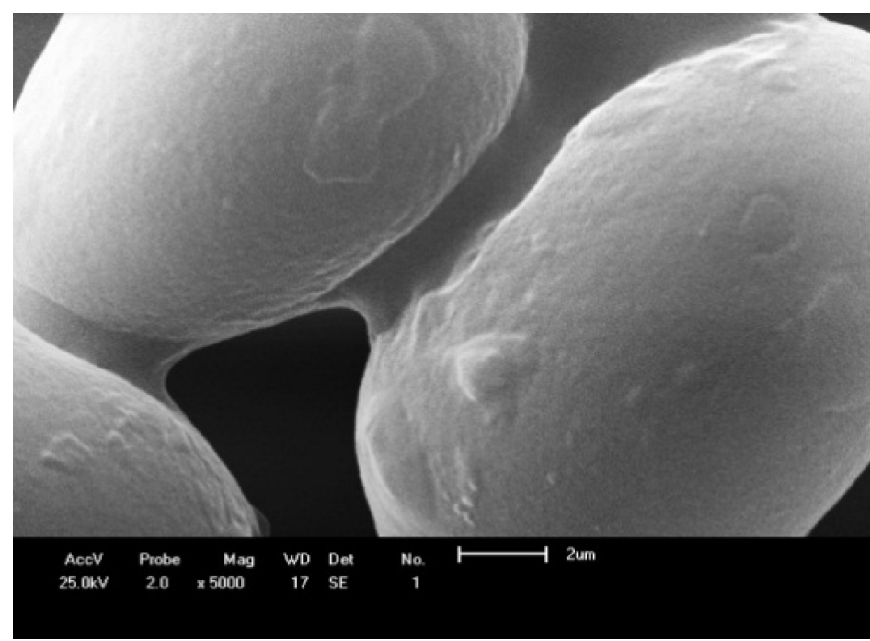

Figura 1. Micrografia em microscópio eletrônico de varredura (MEV) do amido extraído da amêndoa da manga Tommy Atkins - Aumento de 1000x (A); Aumento de 5000x (B)

Os grânulos do amido das amêndoas da manga apresentaram formato irregular com predominância de formatos esféricos a elipsoidais e tamanhos diferenciados (Figura 1A). A superfície dos grânulos apresentou-se lisa com algumas ranhuras causadas provavelmente pelo método de extração (Figura 1B).

Resultados semelhantes foram encontrados por Kaur et al. (2004) que observaram, pela mesma metodologia para o amido obtido de amêndoas de manga de 5 cultivares indianos, tamanho de pequeno a grande e formato de oval a elíptico. 
A forma e o tamanho dos grânulos de amido podem variar de acordo com espécies de plantas e maturação, como Leonel \& Cereda (2002) que observaram os grânulos de amido da araruta comum por microscopia eletrônica e mostraram os grânulos de forma circular e ovalada, de tamanhos variando de 9 a $42 \mu \mathrm{m}$, com predomínio na faixa de $20 \mu \mathrm{m}$.

Na Tabela 3 se apresentam os resultados do Número Mais Provável (NMP) de coliformes totais, coliformes termotolerantes, Bacillus cereus no amido da amêndoa da manga.

Tabela 3. Qualidade microbiológica do amido obtido da amêndoa da manga

\begin{tabular}{lcc}
\hline Parâmetros & Amido extraído & Padrão ANVISA \\
Coliformes a $\left.35^{\circ} \mathrm{C} \mathrm{(NMP} \mathrm{g}{ }^{-1}\right)$ & $1,2 \times 10^{2}$ & - \\
Coliformes a $45^{\circ} \mathrm{C}\left(\mathrm{NMP} \mathrm{g}{ }^{-1}\right)$ & Ausência & $10^{2}$ \\
Salmonella sp $25 \mathrm{~g}^{-1}$ & Ausência & Ausência \\
Bacillus Cereus (UFC g-1) & Ausência & $3 \times 10^{3}$ \\
Bolores e Leveduras & $0,83 \times 10^{2}$ & - \\
\hline "Resolução RDC n.12 de 02/01/2001 (Brasil, 2001)
\end{tabular}

As análises microbiológicas apresentaram valores satisfatórios com ausência de coliformes termotolerantes, Salmonella e Bacillus cereus, dentro dos padrões estabelecidos pela ANVISA (Brasil, 2001) e com baixa contaminação por coliformes totais e bolores e leveduras representando um produto confiável para ser utilizado como ingrediente em formulados alimentícios para o consumo humano.

Quando estudada a propriedade funcional do amido de gelificação, a concentração mínima para formação de gel (LGC) é usada como índice para o amido da amêndoa da manga Tommy Atkins, foi de 6\%, apresentando gelatinização negativa na concentração de $2 \%$ (estado líquido) e positiva nas concentrações de 4 a 14\% (estado de viscoso a gel muito firme).

Ao utilizar o amido extraído como espessante em bebida láctea fermentada sabor morango, realizou-se a análise sensorial, que contou com 60 provadores, sendo: $71,67 \%$ do gênero feminino e $28,33 \%$ do gênero masculino, com frequência de idade de $55 \%$ até 30 anos, $40 \%$ até 20 anos e $5 \%$ acima de 30 anos. Os provadores apresentaram grau de escolaridade de $76,67 \%$ cursando o ensino superior e $15 \%$ dos provadores com ensino superior completo. Com relação à frequência de consumo de bebida láctea ou iogurte, $21,67 \%$ dos provadores consumiam pelo menos uma vez por semana este tipo de produto, $48,33 \% \mathrm{o}$ consumia de duas a três vezes por semana, $13,33 \%$ o consumiam diariamente e $16,67 \%$ apenas 1 ou 2 vezes por mês.

As bebidas lácteas fermentadas sabor morango elaboradas com concentrações diferentes de amido, foram submetidas ao teste de aceitação, através dos atributos aceitação, textura e aparência, cujos escores médios estão representados na Tabela 4.
As médias dos experimentos nos diferentes atributos analisados não diferiram estatisticamente entre si, em nível de $5 \%$ de significância; no entanto, os valores médios dos atributos variaram de 6,10 a 7,18, equivalentes aos termos hedônicos de "gostei ligeiramente" a "gostei muito". Quando comparados com a bebida láctea comercial, os produtos elaborados não diferiram estatisticamente sinalizando boa aceitação do produto elaborado. A Figura 2 apresenta histogramas de frequência para aceitação global (A) tal como, também, os atributos textura (B) e aparência (C) respectivamente, das bebidas lácteas experimentais e da amostra comercial.

As bebidas lácteas analisadas obtiveram bom índice de aceitação, variando de 66,67 a $98,33 \%$ entre as amostras,
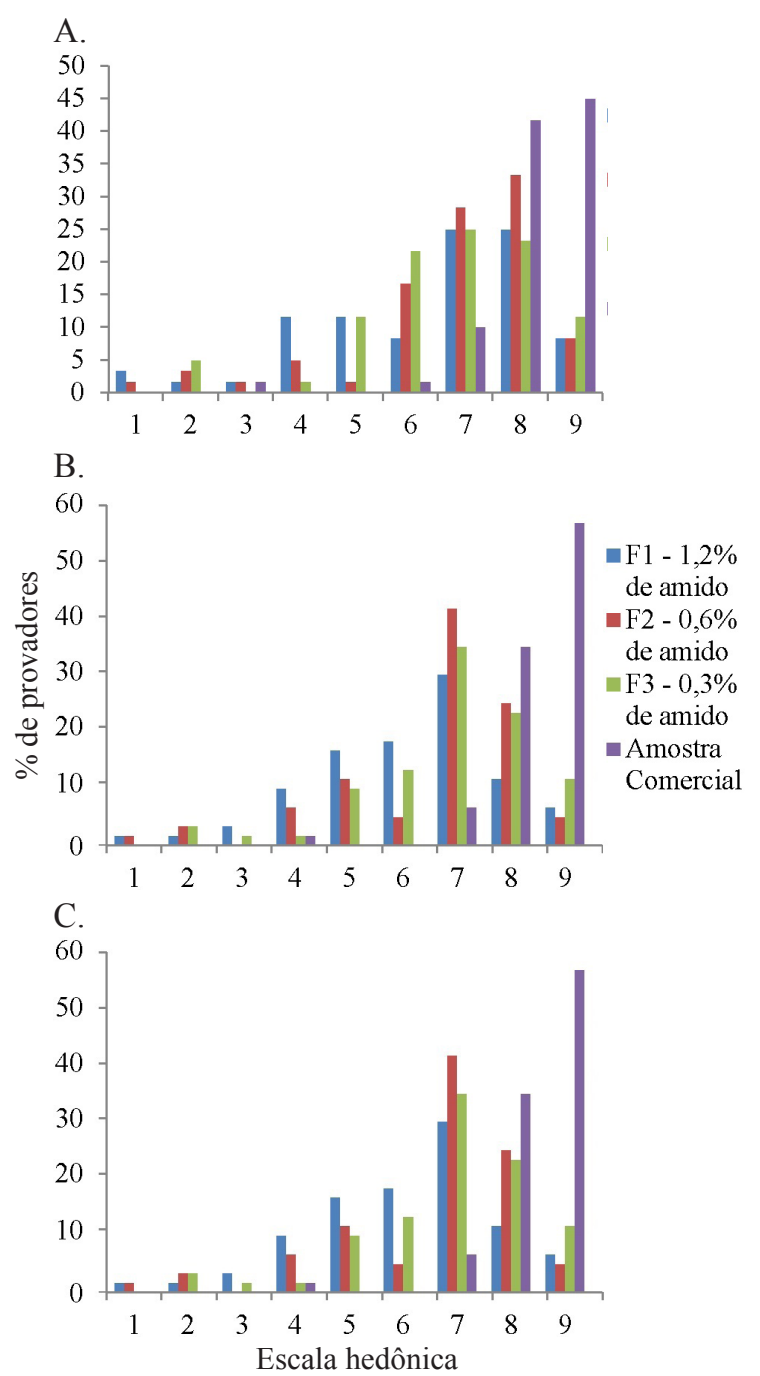

Figura 2. Histogramas de frequência para aceitação global (A), textura (B) e aparência (C) para as bebidas lácteas experimentais e da amostra comercial

Tabela 4. Análise sensorial ${ }^{*}$ das formulações de bebida láctea com diferentes concentrações de amido da amêndoa da manga Tommy Atkins e da bebida láctea comercial

\begin{tabular}{lcccc}
\hline Atributos & \multicolumn{4}{c}{ Bebida láctea } \\
\cline { 2 - 5 } sensoriais & Com $\mathbf{1 , 2} \%$ de amido & Com 0,6\% de amido & Com 0,3\% de amido & Comercial \\
Aceitação & $6,40 \pm 1,95 \mathrm{a}$ & $6,82 \pm 1,75 \mathrm{a}$ & $6,72 \pm 1,66 \mathrm{a}$ & $8,25 \pm 1,00 \mathrm{a}$ \\
Textura & $6,60 \pm 1,75 \mathrm{a}$ & $7,18 \pm 1,40 \mathrm{a}$ & $7,05 \pm 1,52 \mathrm{a}$ & $8,08 \pm 1,03 \mathrm{a}$ \\
Aparência & $6,10 \pm 1,72 \mathrm{a}$ & $6,60 \pm 1,70 \mathrm{a}$ & $6,82 \pm 1,58 \mathrm{a}$ & $8,42 \pm 0,85 \mathrm{a}$ \\
\hline
\end{tabular}

${ }^{\star}$ Nota: média das análises de 60 provadores não treinados seguidas de seus respectivos desvios padrões. Letras iguais na mesma linha não diferem estatisticamente pelo teste de Tukey a 0,05 de significância 
caracterizando boa aceitação do produto elaborado. A formulação com maior índice de aceitação foi a comercial, com 98,33\%, seguida da formulação com $0,6 \%$ de amido com $86,67 \%$, formulação com $0,3 \%$ de amido com $81,67 \%$. A formulação com $1,2 \%$ de amido apresentou baixo índice de aceitação, 66,67\%. Com relação ao índice de rejeição, a formulação com 1,2\% de amido foi a que obteve maior índice, com $18,33 \%$ e a amostra comercial o menor índice, com $1,67 \%$.

$\mathrm{O}$ atributo textura foi o que obteve maior índice de aceitação comparado com os outros atributos analisados variando de 80,00 a $98,33 \%$ e índice de rejeição variando de 0 a 8,33\%. A amostra comercial apresentou maior índice de aceitação com $98,33 \%$, seguida das formulações com $0,6 \%(88,33 \%)$, $0,3 \%(83,33 \%)$ e $1,2 \%(80,00 \%)$ de amido. A formulação com $0,3 \%$ de amido não obteve índice de rejeição e a formulação com $1,2 \%$ de amido obteve índice de $8,33 \%$. As amostras com maior teor de amido não apresentaram boa aceitação quanto ao atributo textura provavelmente por apresentar uma viscosidade acima do aceitável para este tipo de produto evidenciando o uso do amido em estudo em quantidade reduzida na produção de bebidas lácteas. Com relação ao atributo aparência, as amostras elaboradas apresentaram índice de aceitação de 83,33\% para a formulação com $0,3 \%$ de amido, seguido da formulação com $0,6 \%$ de amido com $76,67 \%$ de aceitação e com o menor índice a formulação com $1,2 \%$ de amido com $66,67 \%$ de aceitação e consequentemente maior de rejeição com $16,67 \%$.

Observa-se, para os atributos analisados, que a frequência dos resultados sensoriais aceitáveis ou índice de aceitação, quando somados os pontos da escala de 6 "gostei ligeiramente" a 9 "gostei muitíssimo", esteve superior a 70\% em sua maioria, sendo a formulação com $0,3 \%$ de amido a mais aceita entre as elaboradas. A Figura 3 apresenta o histograma de frequência para intenção de compra para as bebidas lácteas experimentais e da amostra comercial.

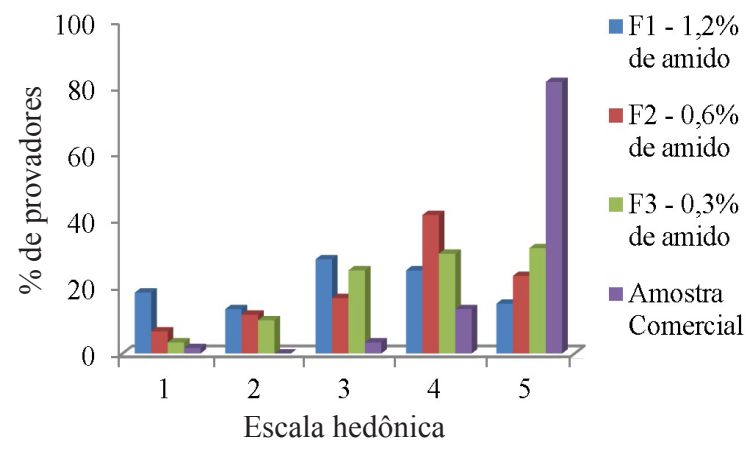

Figura 3. Histogramas de frequência para a intenção de compra para as bebidas lácteas experimentais e da amostra comercial

Com referência à intenção de compra do produto elaborado, a formulação utilizando $0,3 \%$ de amido obteve valor médio de $3,80( \pm 1,18)$, seguida da formulação com $0,6 \%$ de amido com $3,63( \pm 1,16)$ e da formulação com $1,2 \%$ de amido com 3,05 $( \pm 1,32)$ com escores variando de "talvez comprasse, talvez não comprasse" a "possivelmente compraria". A amostra comercial obteve maior escore que as amostras elaboradas experimentalmente com 4,73 $( \pm 0,69)$ (Figura 3).

A bebida láctea fermentada elaborada utilizando-se o amido das amêndoas da manga Tommy Atkins a 0,3\% foi a escolhida para ser caracterizada por possuir melhores características sensoriais comparada com as outras formulações, como apresentado na Tabela 5.

Tabela 5. Análise físico-química de bebida láctea fermentada sabor morango utilizando-se 0,3\% de amido extraído de amêndoa de manga como espessante

\begin{tabular}{cc}
\hline Parâmetros analisados & Bebida láctea produzida \\
Umidade (\%) & $79,18 \pm 0,05$ \\
EST*$^{*}(\%)$ & $20,82 \pm 0,05$ \\
Cinzas (\%) & $0,92 \pm 0,07$ \\
Proteínas (\%) & $2,03 \pm 0,38$ \\
Lipídeos (\%) & $3,49 \pm 0,37$ \\
${ }^{\circ B r i x}$ & $20,83 \pm 0,38$ \\
Acidez ( $\left.{ }^{\circ} \mathrm{D}\right)$ & $60,00 \pm 0,01$ \\
pH & $4,31 \pm 0,01$ \\
\hline
\end{tabular}

${ }^{*}$ EST - Extrato seco total; Médias dos resultados em triplicata seguidas do respectivo desvio padrão

Como espessante, a bebida láctea elaborada com $0,3 \%$ de amido da amêndoa da manga apresentou teor de umidade de $79,18 \%$ com extrato seco total de 20,82\%. Gajo et al. (2010) obtiveram, em pesquisa sobre bebidas lácteas fermentadas de leite de ovelha com diferentes concentrações de soro, valores médios para extrato seco total de 18,93\%. Quanto aos teores de cinzas a bebida apresentou média de $0,92 \%$, valores acima dos encontrados por Cunha et al. (2008), 0,62\%, em estudo sobre bebidas lácteas e leite fermentado adicionados de probióticos. O teor de proteínas, de 2,03\%, está dentro dos padrões da legislação que diz no mínimo de $1,8 \%$ de proteínas para bebidas lácteas fermentadas, valor bem próximo ao constatado por Almeida et al. (2001) que encontraram valores de proteína entre 1,94 e $2,08 \%$ em bebidas lácteas fermentadas preparadas com soro de queijo minas frescal.

\section{Conclusões}

1. As amêndoas do endocarpo da manga Tommy Atkins apresentaram alta concentração de amido com bom rendimento de extração, inodoro, insípido e boa qualidade, além da isenção de micro-organismos patogênicos.

2. A bebida láctea fermentada elaborada mostrou-se viável para comercialização, por apresentar boas características sensoriais e físico-químicas utilizando apenas $0,3 \%$ de amido da amêndoa da manga como espessante. Considerando essas características, o amido apresentou características desejáveis podendo ser largamente utilizado como alternativa na indústria de alimentos.

\section{Literatura Citada}

Adebowale, K. O.; Afolabi, T. A.; Oluowolabi, B. I. Functional, physicochemical and retrogradation properties of sword bean (Canavalia gladiata) acetylated and oxidized starches. Carbohydrate Polymers, v.65, p.93-101, 2006.

Almeida, K. E. de; Bonassi, I. A.; Roça, R. de O. Características físicas e químicas de bebidas lácteas fermentadas e preparadas com soro de queijo minas frescal. Ciência e Tecnologia de Alimentos, v.21, p.187-192, 2001. 
Benevides, S. D.; Ramos, A. M.; Stringheta, P. C.; Castro, V. C. Qualidade da manga e polpa da manga Ubá. Ciência e Tecnologia de Alimentos, v.28, p.571-578, 2008.

Brasil. Ministério da Agricultura. Laboratório Nacional de Referência Animal (LANARA). Métodos analíticos oficiais para controle de produtos de origem animal e seus ingredientes: II Métodos físicos e químicos. Brasília: Ministério da Agricultura, 1981. v.2. 188p.

Brasil. Ministério da Saúde. Agência Nacional de Vigilância Sanitária (ANVISA). Resolução RDC n.12 de 02/01/2001. Regulamento técnico sobre padrões microbiológicos para alimentos. Brasília: Ministério as Agricultura, 2001. 67p.

Brasil. Métodos físico-químicos para análise de alimentos. Métodos físicos e químicos para análise de alimentos. 4.ed. São Paulo: Instituto Adolfo Lutz, 2005a. 1018p.

Brasil. Ministério da Saúde/Agência Nacional de Vigilância Sanitária. Instrução Normativa n.16, de 23 de agosto de 2005. Regulamento Técnico de Identidade e Qualidade de Bebida Láctea. Diário Oficial da União, 2005b. Seção 1. 7p.

Capitani, C. D.; Pacheco. M. T. B.; Gumerato, H. F.; Vitali, A.; Schmidt, F. L. Recuperação das proteínas do soro de leite por meio de coacervação com polissacarídeo. Pesquisa Agropecuária Brasileira, v.40, p.1123-1128, 2005.

Cavalcanti, M. T.; Silva, V. C.; Costa, T. S.; Florêncio, I. M.; Florentino, E. R. Obtenção do amido do endocarpo da manga para diversificação produtiva na indústria de alimentos. Revista Verde de Agroecologia e Desenvolvimento Sustentável, v.6, p.80-83, 2011.

Chowdary, G. V.; Harikrishna, S.; Hanumantha R. A. O. Optimization of enzyme hydrolysis of mango kernel starch by response surface methodology. Bioprocess Engineering, v.23, p.681-685, 2000.

Cunha, T. M.; Castro, F. P. de; Barreto, P. L. M.; Benedet, H. D.; Prudêncio, E. S. Avaliação físico-química, microbiológica e reológica de bebida láctea e leite fermentado adicionados de probióticos. Semina: Ciências Agrárias, v.29, p.103-116, 2008.

Daiuto, E. R.; Cereda, M. P.; Carvalho, L. J. C. B. Características e propriedades do amido extraído de camadas do tecido da raiz de mandioca cv. Mico (Manihot Sculenta Crantz), Brazilian Journal of Food and Technology, v.5, p.217-223, 2002.

Gajo A. A.; Carvalho, M. S.; Abreu L. R.; Pinto S. M. Avaliação da composição química e características sensoriais de bebidas lácteas fermentadas elaboradas com leite de ovelha. Revista do Instituto de Laticínio Cândido Toste, v.65, p.59-65. 2010.

Kaur, M.; Singh, N.; Sandhu, K. S.; Guraya, H. S. Physicochemical, morphological, thermal, and rheological properties of starches separated from kernels of some Indian mango cultivars (Mangifera indica L.). Food Chemistry, v.85, p.131-140, 2004.
Kaur, M.; Singh, N.; Sandhu, K. S.; Guraya, H. S. Physicochemical, thermal and pasting properties of starches separated from different potato cultivars grown at different locations. Food Chemistry, v.101, p.643-651, 2006.

Labanca, R. A.; Silva, C. M. G.; Glória, M. B. A. Starch levels in refrigerated and frozen chicken based meat products. Brazilian Archives of Biology and Tecnology, v.42, p.1-6, 1999.

Lawal, O. S.; Adebowale, K. O. Physicochemical characteristics and thermal properties of chemically modified jack bean (Canavalia ensiformis) starch. Carbohydrate Polymers, v.60, p.331-341, 2005.

Leonel, M.; Cereda, M. P. processamento de araruta (Maranta arundinacea) para extração e caracterização da fração amilácea. Brazilian Journal of Food Technology, v.5, p.151155, 2002.

Leonel, M.; Sarmento, S. B. S.; Cereda, M. P.; Cãmara, F. L. A. Extração e caracterização de amido de jacatupé (Pachyrhizus ahipa). Ciência e Tecnologia de Alimentos, v.23, p.362-365, 2003.

Lira, H. de L.; Silva, M. C. D.; Vasconcelos, M. R. dos S.; Lira, H. de L.; Lopez, A. M. Microfiltração do soro de leite de búfala utilizando membranas cerâmicas como alternativa ao processo de pasteurização. Ciência e Tecnologia de Alimentos, v.29, p.33-37, 2009.

Oliveira, L. F.; Nascimento, M. R. F.; Borges, S. V.; Ribeiro, P. C. N.; Ruback, V. R. Aproveitamento alternativo da casca do maracujá-amarelo (Passiflora edulis F. Flavicarpa) para produção de doce em calda. Ciência e Tecnologia de Alimentos, v.22, p.259-262, 2002.

Serrano, P. O.; Franco, C. M. L. Modificações hidrotérmicas ("Annealing") e hidrólise enzimática do amido de mandioca. Brazilian Journal of Food Technology, v.8, p.220-232, 2005.

Sgarbieri, V. C. Propriedades fisiológicas-funcionais das proteínas do soro de leite. Revista de Nutrição, v.17, p.397409, 2008.

Velan, M.; Krishnan, M. R. V.; Lakshmanan, C. M. Conversion of mango kernel starch to glucose syrups by enzymatic hydrolysis. Bioprocess and Biosystem Engineering, v.12, p.323-326. 1995.

Vieira, P. A. F.; Queiroz, J. H.; Vieira, B. C.; Mendes, F. Q.; Barbosa, A. A.; Muller, E. S.; Sant'Ana, R. C. O.; Moraes, G. H. K. Caracterização química do resíduo do processamento agroindustrial da manga (Mangifera indica L.) var. Ubá. Alimentos e Nutrição, v.20, p.617-623, 2009.

Zein, R. E.; El-Bagoury, A. A.; Kassab, H. E. Chemical and nutritional studies on mango seed kernels.Journal of Agricultural Science, v.30, p.3285-3299, 2005. 